\title{
Proteomic and Functional Analyses Reveal That Kallikrein 6 Enhances Communicating Hydrocephalus by Injuring Neuronal Synapses
}

\section{Lei Yuan}

Shanghai 6th Peoples Hospital Affiliated to Shanghai Jiaotong University School of Medicine

\section{Dongdong Zou}

Shanghai 6th Peoples Hospital Affiliated to Shanghai Jiaotong University School of Medicine

\section{Xia Yang}

Shanghai 6th Peoples Hospital Affiliated to Shanghai Jiaotong University School of Medicine

Xin Chen ( $\square$ masterchx@hotmail.com )

Shanghai 6th Peoples Hospital Affiliated to Shanghai Jiaotong University School of Medicine https://orcid.org/0000-0002-6247-7862

\section{Youming Lu}

Shanghai 6th Peoples Hospital Affiliated to Shanghai Jiaotong University School of Medicine

\section{Aijun Zhang}

Shanghai 6th Peoples Hospital Affiliated to Shanghai Jiaotong University School of Medicine

\section{Pengqi Zhang}

Shanghai 6th Peoples Hospital Affiliated to Shanghai Jiaotong University School of Medicine

\section{Fance Wei}

Shanghai 6th Peoples Hospital Affiliated to Shanghai Jiaotong University School of Medicine

\section{Research Article}

Keywords: cerebrospinal fluid, communicating hydrocephalus, kallikrein-6, Appl2, Nav2, Nrn1

Posted Date: May 24th, 2021

DOI: https://doi.org/10.21203/rs.3.rs-403838/v1

License: (c) (1) This work is licensed under a Creative Commons Attribution 4.0 International License. Read Full License 


\section{Abstract}

Communicating hydrocephalus $(\mathrm{CH})$ is a common neurological disorder caused by a blockage of cerebrospinal fluid. In this study, we aimed to explore the potential molecular mechanism underlying $\mathrm{CH}$ development. Quantitative proteomic analysis was performed to screen the differentially expressed proteins (DEPs) between patients with and without $\mathrm{CH}$. A CH rat model was verified by Hoechst staining, and the co-localization of the target protein and neuron was detected using immunofluorescence staining. Loss-of-function experiments were performed to examine the effect of KLK6 on the synapse structure. A total of 11 DEPs were identified, and kallikrein 6 (KLK6) expression was found to be significantly upregulated in patients with $\mathrm{CH}$ compared with that in patients without $\mathrm{CH}$. The $\mathrm{CH}$ rat model was successfully constructed, and KLK6 was found to be co-localized with neuronal nuclei in brain tissue. The expression level of KLK6 in the $\mathrm{CH}$ group was higher than that in the control group. After interference of KLK6 expression, the expression levels of synapsin-1 and PSD95 in neuronal cells were increased, and the length, number, and structure of synapses were significantly improved. The transcriptome profile (PRJNA719985) after interference of KLK6 expression was obtained, and 5,681 differentially expressed genes (DEGs) were identified. The upregulated DEGs of Appl2, Nav2, and Nrn1 may be involved in the recovery of synaptic structures after interference of KLK6 expression. Collectively, KLK6 participates in the development of $\mathrm{CH}$ and might provide a new target for $\mathrm{CH}$ treatment.

\section{Introduction}

Communicating hydrocephalus $(\mathrm{CH})$, a common neurological disorder, is associated with cognitive decline and severe deterioration of the quality of life of patients. $\mathrm{CH}$ is known to be etiologically heterogeneous and can be caused by subarachnoid hemorrhage, leptomeningeal metastasis, trauma, and tumors (Drewes et al. 2014). The probability of $\mathrm{CH}$ after subarachnoid hemorrhage is as high as $67 \%$ and as low as 13\% (Yang et al. 2013). Although the brain is less prone to hydrocephalus because of the compensatory absorption of cerebrospinal fluid (CSF), it is irreversible once it occurs, and patients often require long-term shunt therapy (Xu 2016). Carelessness related to $\mathrm{CH}$ can lead to death or disability. Subarachnoid space fibrosis leads to the development of multiple forms of $\mathrm{CH}$ due to impaired CSF flow and reduced CSF drainage (Botfield et al. 2013). However, more than 100 years after the first experimental study of hydrocephalus, the molecular mechanism of $\mathrm{CH}$ following subarachnoid hemorrhage (SAH) remains unknown.

The human kallikrein 6 (KLK6) gene encodes a member of the KLK-related peptidase family, also known as the human cancer biomarker family, which comprises at least 15 members and is located on chromosome 19q13.3-13.4 (Paliouras et al. 2007). Currently, proteome sequencing is usually employed to identify differentially expressed proteins (DEPs) in specific biological backgrounds. Its combination with mechanistic experiments allows effective exploration of the potential functions of KLK proteins. Kryza et al. identified the involvement of KLK14 in the aggressive characteristics of prostate cancer using a method called cell-secreted proteomics (Kryza et al. 2020). In-depth proteomic and biochemical studies on cervical-vaginal fluid demonstrated that KLK was involved in the regulation of the female 
reproductive system (Muytjens et al. 2016). However, there have been no studies on the application of proteomics to study KLK6-related functions in $\mathrm{CH}$. The expression of KLK6 in central nervous system (CNS) diseases is heterogeneous, such as upregulation of KLK6 expression in CNS inflammatory response and downregulation of KLK6 expression in Alzheimer's disease (AD) and Parkinson's disease (Ogawa et al. 2000). A previous study showed that KLK6 is expressed in aneurysmal SAH and as a serum prognostic biomarker (Martinez-Morillo et al. 2012).

$K L K 6$ encodes an enzyme with trypsin-like properties that degrades the extracellular matrix (Bayani \& Diamandis 2011). The abnormal decline in extracellular matrix protein in CSF is associated with various neurological diseases, such as SAH (Suzuki et al. 2020), stroke (Kawakita et al. 2019), and traumatic brain injury (Minta et al. 2019). These findings suggest that KLK6 plays a vital role in neurological diseases, but its detailed function in $\mathrm{CH}$ after $\mathrm{SAH}$ remains unclear. Therefore, we aimed to explore the effects of KLK6 on neurons by quantitative proteomics and functional loss analysis and provide a theoretical basis and therapeutic target for $\mathrm{CH}$ prevention and treatment.

\section{Materials And Methods}

\section{Ethics statement}

The study protocol was approved by the Institutional Ethics Committee of The Affiliated Sixth People's Hospital, Shanghai Jiaotong University. All participants were fully informed and signed written informed consent in this study. All efforts were made to minimize rat suffering.

\section{Patients}

The data of patients with cerebral hemorrhage accompanied by $\mathrm{CH}(\mathrm{n}=20)$ and of patients with cerebral hemorrhage without $\mathrm{CH}(\mathrm{n}=20)$ were collected. The clinical profiles of patients with SAH are shown in Table S1. The patients were diagnosed according to the standard clinical and laboratory criteria and referred from our neurology department. The following cases were excluded: normal-pressure hydrocephalus due to normal production; hydrocephalus due to overproduction, such as choroid plexus papilloma evacuation of hydrocephalus; or cases of reduced volume secondary to brain parenchyma. Of these, three patients and five healthy controls were included in proteome sequencing.

\section{Protein extraction and liquid chromatography-tandem mass spectrometry}

Proteins were extracted from CSF samples of three patients with $\mathrm{CH}$ and five patients without $\mathrm{CH}$ as previously described (Wan et al. 2019). Briefly, the BCA kit (Thermo Scientific, USA) was used to extract and measure the protein concentration. Then, the proteins were separated into fractions using SDS-PAGE and unqualified samples by SDS-PAGE were removed in this step. Next, the proteins in each fraction were cleaved into peptides using in-gel digestion with trypsin (Promega, Madison, WI, USA). Finally, the peptides were stored at $-20^{\circ} \mathrm{C}$ until liquid chromatography-tandem mass spectrometry (LC-MS/MS) analysis. LC-MS/MS analysis was performed using Orbitrap QE (Thermo Scientific) with higher energy 
collisional dissociation mode for quantitative analysis of label-free proteomics. The parameter settings were as described previously (Barkovits et al. 2018).

\section{Protein identification and analysis}

The raw MS2 data were searched using Maxquant version 1.6.0.1 (Thermo Scientific) against the human UniProt database. Carbamidomethyl (Cys) was set as a fixed modification. The variable modifications included oxidation (Met) and acetyl (protein N-term). A positive identification of peptide length was required to contain a minimum of seven amino acids and a maximum of one peptide PEP. The tolerances of MS/MS were set as $20 \mathrm{ppm}$. The false discovery rates (FDRs) of the peptide-spectral match and protein identification were set as 0.01 . The total protein approach method (Wisniewski \& Rakus 2014) was used to calculate the protein expression. Proteins with a P-value of $<0.05$ were considered DEPs. Finally, Gene Ontology (GO) functional and Kyoto Encyclopedia of Genes and Genomes (KEGG) pathway enrichment analysis were applied on DEPs, and DEPs were corrected using principal component analysis (PCA) via the pipeline process. The spectral data were deposited to the Figshare website (https://figshare.com/account/login) with the dataset DOI: 10.6084/m9.figshare.12335288.

\section{Enzyme-linked immunosorbent assay (ELISA) analysis}

The expression levels of KLK6 in CSF and blood from 20 patients with $\mathrm{CH}$ and 20 patients without $\mathrm{CH}$ were measured using a commercial ELISA 96T Kit (Boster Biological Technology, China) according to the manufacturer's instructions. This experiment was conducted in duplicate. The absorption value was measured at a wavelength of $450 \mathrm{~nm}$ using a microplate reader, and the KLK6 expression level was calculated using standards.

\section{Rat model and sample collection}

Wistar rats were purchased from Yingbio (Shanghai, China), and thirty 12-week-old male Wistar rats were randomly divided into a healthy control group and a model group. A CH rat model was constructed according to a previously described method (Chen et al. 2010; Cherian et al. 2003). Briefly, citrated rat venous blood and artificial CSF (ACSF) were injected stereotactically into the lateral cerebral ventricles of the model group and the lateral ventricle of the control group, respectively. The rats in the two groups were fed for 3 weeks in the same environment and weighed daily. After 3 weeks, they were sacrificed to obtain brain tissue, which was paraffin-embedded for subsequent staining.

\section{Hoechst staining}

Hoechst staining was used to observe the apoptosis and morphological changes of neurons. Paraffinembedded brain tissues were cut into 4- $\mu \mathrm{m}$-thick slices and stained using the Hoechst staining kit (Beyotime, Shanghai). The slices were rinsed twice with phosphate buffer solution for 3 min each time. After adding Hoechst staining solution, the paraffin slices were incubated at $37^{\circ} \mathrm{C}$ for $10 \mathrm{~min}$ and detected under a fluorescence microscope. The nuclei of apoptotic cells showed strong fluorescence, whereas the nuclei of nonapoptotic cells showed weak fluorescence. 


\section{Immunofluorescence staining}

The transfected neurons grew adherent to the slides and were fixed with $4 \%$ paraformaldehyde for 10 min. The slides and 4-mm-thick paraffin-embedded sections were used for immunofluorescence staining. Briefly, the slides and paraffin sections were permeated with $0.1 \%$ Triton X-100 and sealed with $3 \%$ bovine serum albumin, followed by incubation with primary antibodies overnight. After washing them three times, the sections were incubated with secondary antibodies for $2 \mathrm{~h}$ and then stained with DAPI (Invitrogen, Carlsbad, CA, USA) for $15 \mathrm{~min}$ at room temperature. Finally, with the sections were imaged under a microscope. Rat tissue sections were prepared with KLK6 (1:250; Santa Cruz, China) and neuronal nuclei (NeuN) (1:300; Cell Signaling, USA) proteins as primary antibodies, and the neuron lines were treated with microtubule-associated protein 2 (MAP-2) (1:500; Signalway Antibody LLC, USA) protein as a primary antibody.

\section{Cell culture and knockdown of KLK6 expression using small interfering RNA (siRNA)}

Primary rat hippocampal neuron cells were purchased from Procell Life Science \& Technology (Wuhan, China) and cultured in a Cell Culture Flask (\#353108, FALCONNest) containing RPMI medium (\#CM-R107, Procell) at $37{ }^{\circ} \mathrm{C}$ with $5 \% \mathrm{CO}_{2}$. Three siRNA targeting $\mathrm{KLK} 6$ and one non-targeting control were synthesized by Gibico (Shanghai, China), as showed in Table S2. According to the manufacturer's instructions, the KLK6 siRNA or the control siRNA were transfected into neurons for $48 \mathrm{~h}$ using Lipofectamine 2000 (Invitrogen). The transfection efficiency was determined using qRT-PCR and western blotting.

\section{Western blotting}

The total proteins of cultured neurons were obtained using RIPA (Thermo, USA) to lysate and measured using the BSA kit (TaKaRa, Dalian). Next, aliquots containing $20 \mu \mathrm{g}$ of protein were electrophoresed on $10 \%$ SDS-PAGE and transferred onto PVDF membranes (ThermoScientific, Madison, WI, USA). The PVDF membranes were blocked with TBST solution containing $5 \%$ skim milk at room temperature for $3 \mathrm{~h}$ and incubated with primary antibodies (including anti-KLK6, anti-PSD95, and anti-YN1-specific antibodies; the dilution ratio was $1: 1000)$ overnight at $4^{\circ} \mathrm{C}$ and with HRP-conjugated secondary antibody (1:10000) at room temperature for $1 \mathrm{~h}$. The protein bands were detected using a high-sensitivity ECL luminescence kit (ThermoScientific, Madison, WI, USA) and imaged using a chemiluminescence imaging analysis system.

\section{Quantitative reverse transcription PCR (qRT-PCR)}

TRIzol reagent (Invitrogen Life Technologies, Inc.) was used to extract total RNA from neurons according to the manufacturer's protocol. The RNA concentration and purity were determined using a microspectrophotometer (Tiangen Biotech Co., Ltd.). RNA was reversely transcribed into first-strand cDNA using the RevertAid First-Strand cDNA synthesis kit (ThermoScientific, Madison, WI, USA). According to the manufacturer's instruction, the cDNA was amplified using FastStart Universal SYBR Green Master mix on a QuantStudio 6 Flex Real-Time PCR System (Thermo Fisher Scientific, Inc.). All primers used in this 
study were synthesized by Sangon Biotech (Shanghai, China) (Table S2). GAPDH served as a housekeeping gene, and gene expressions were normalized using the $2^{-\triangle \Delta C q}$ method.

\section{Transcriptome sequencing of neuron}

Total RNA was isolated from primary rat hippocampal neuron cells transfected with siRNA-KLK6 or siRNA-NC using TRIzol reagent. The RNA concentration and purity were determined using a microspectrophotometer. Ribosomal RNA was eliminated from total RNA, and the remaining RNA was used to construct the cDNA library using the TruSeq Stranded RNA Sample Preparation Kit (Illumina, San Diego, CA, USA). Then, the cDNA library was purified on the AMPure XP system, and the quality of the library was assessed using an Agilent Bioanalyzer 2100 system. Finally, the cDNA library was subjected to RNA sequencing on an Illumina HiSeq 2500 platform with a paired-end 150-bp read run. FastQC (http://www.bioinformatics.babraham.ac.uk/projects/fastqc/) was used for the quality control of raw reads. The gene expression was normalized by fragments per kilobase of exon per million fragments mapped. The DEGSeq algorithm was utilized to screen differentially expressed genes (DEGs, with a significance threshold of Log2FC $>1$ or $<-1$ and FDR $<0.05$. The DEGs were utilized for functional annotation and enrichment analysis of GO and KEGG, using an R-based hypergeometric distribution. The RNA-seq data generated in this study is available in National Center for Biotechnology Information under accession number PRJNA719985.

\section{Statistical analysis}

All data were analyzed using SPSS version 17.0 and presented as the mean \pm SD. Student's t-test was used for comparisons between the two groups. $\mathrm{P}<0.05$ indicated statistical significance.

\section{Results}

\section{Overall analysis of proteome sequencing}

We initially included three patients with $\mathrm{CH}$ samples and five patients without $\mathrm{CH}$ samples (non- $\mathrm{CH}$ ) for proteome sequencing to avoid data loss of credibility due to insufficient sample repetition. The SDS-PAGE results showed (Fig. S1) that protein patterns from two non-CH controls were unreliable, at which point only the remaining three groups were used for subsequent analysis. The peptide distribution, relative protein molecular weight, peptide length, and proteins sequence coverage are shown in Fig. S2. These results provided the confidence of our MS2 data. We obtained 388,652 total spectra, and the number of spectra matched by the identified peptide segment was 41,139 . Among them, a total of 6,815 peptides and 1,008 protein groups were identified (Table S3).

\section{Comparative proteome analysis of non- $\mathrm{CH}$ vs. $\mathrm{CH}$}

Given the differences in gene signature between different samples of DEPs, we conducted a PCA analysis of the DEPs. The six components explained $100 \%$ of the dataset variation, as shown in Fig. 1A. The 
principal components PC1 and PC2 explained $76.5 \%$ and $14.4 \%$ of the total variation, respectively. There were considerable differences in proteins between the two groups, and the result indicated that the non$\mathrm{CH}$ group and the $\mathrm{CH}$ group were separated in PCA. Notably, we acquired 212 proteins with quantitative information in six samples after decontamination from 1,008 protein groups (Fig. 1B). In addition, we identified 11 significant DEPs. Among them, the expressions of 10 proteins were upregulated and 1 was downregulated in the $\mathrm{CH}$ group compared with those in the non- $\mathrm{CH}$ group (Fig. 1C). The specific information of 11 DEPs is shown in Table S4. Further, the proteins in the non- $\mathrm{CH}$ and the $\mathrm{CH}$ groups were clustered into two groups with different expression patterns (Fig. 1D).

\section{KLK6 is highly expressed in patients with $\mathrm{CH}$}

The expression intensity of 11 DEPs in six samples was determined by the ratio of the expression level of the non- $\mathrm{CH}$ group to that of the $\mathrm{CH}$ group and represented as the value of fold-change (FC). The results showed that only metalloproteinase inhibitor 1 had an $\mathrm{FC}$ value of $>1.5$. This result indicates that metalloproteinase inhibitor 1 expression was downregulated in $\mathrm{CH}$, whereas the expressions of the remaining 10 DEPs were upregulated. Those 10 DEPs included CD44 antigen, Ig heavy chain V-III region TIL/TUR/WAS/POM, histidine-rich glycoprotein, Ig kappa chain V-III region CLL, apolipoprotein A-IV, kallistatin, and KLK6 (Fig. 2A). These 11 DEPs were mainly involved in chemotaxis (GO: 0006935) and the HIF-1 signaling pathway (Table S5). KLK6 is known to be abnormally expressed in many neurological diseases, and its role in $\mathrm{CH}$ is still unclear (Bernett et al. 2002). Therefore, we further investigated the function and mechanism of KLK6 in CH. We detected KLK6 expression in 20 patients with cerebral hemorrhage with or without $\mathrm{CH}$ using ELISA to determine whether KLK6 was differentially expressed in patients with hydrocephalus. As shown in Fig. $2 \mathrm{~B}$ and $2 \mathrm{C}$, compared with the non- $\mathrm{CH}$ controls, in patients with $\mathrm{CH}$, the protein expression level of KLK6 was significantly upregulated in CSF, whereas there was no significant difference in the expression level in blood. In summary, these results indicated that KLK expression was abnormally upregulated in patients with cerebral hemorrhage with $\mathrm{CH}$, suggesting that $\mathrm{KLK} 6$ is involved in the progression of $\mathrm{CH}$.

\section{KLK6 is highly expressed in neurons of $\mathrm{CH}$ model rat}

Using Hoechst staining, the anterior fontanelle and posterior $0.4-\mathrm{mm}$ coronal lateral ventricle with widths $>1 \mathrm{~mm}$ were characterized as hydrocephalus. The brain tissue morphology of rats injected with venous blood reached the standard of hydrocephalus 3 weeks after surgery, which showed significant enlargement of the lateral ventricle, cortex thinning, and mild hippocampus compression (Fig. 3A). However, all rats injected with ACSF exhibited no ventricular enlargement, cortical compression, or thinning (Fig. 3A). Previous research showed that the neurons and synapses of rats underwent significant pathological changes after $\mathrm{CH}$ occurred and that the abnormal function of neurons was closely related to $\mathrm{CH}$. Thus, KLK6 expression in neurons was identified (Chen et al. 2010). Immunofluorescence staining showed that KLK6 and NeuN were co-localized in brain tissue and that the KLK6 expression in brains injected with venous blood was higher than that in brains injected with ACSF (Fig. 3B). These results indicated that the KLK6 was highly expressed in neurons of $\mathrm{CH}$ model rat. 


\section{KLK6 inhibits synaptic protein expression}

The synapse is the basic unit that maintains neuronal signaling, and it is structurally stable during healthy adulthood (Mayford et al. 2012). Our previous study proved that the length and number of axons and dendrites of neurons in an animal model of $\mathrm{CH}$ were significantly reduced. Therefore, we further investigated whether KLK6 induces changes in the expression of structural proteins in the synapses of neurons. For this purpose, we designed three siRNA sequences and one control sequence and efficiently detected the interference. The mRNA and protein expression levels of KLK6 in the neuronal cells significantly decreased after siRNA-249 treatment compared with those in the control group (Fig. 4A and 4B). Hence, siRNA-249 was used in subsequent experiments.

Synapsin-1 is a presynaptic protein, and PSD95 is a post-synaptic protein that marks the density of synaptic proteins (Garcia-Caceres et al. 2010). Thus, both synapsin-1 and PSD95 were used to evaluate the structure of synapses in this study. As shown in Fig. 4C, the expression levels of PSD95 and synapsin1 were significantly elevated in the KLK6-siRNA-249 group compared with that in the control group. These findings indicate that KLK6 inhibits synaptic protein expression. Moreover, MAP-2 is necessary to maintain microtubule stability and guide microtubule dynamics and is considered a marker of neuron and microtubulin interaction (Le Large et al. 2019). MAP-2-labeled immunofluorescence staining was performed to detect the number and length of synapses in neurons after interference of KLK6 expression. The fluorescence signal of MAP-2 significantly increased with KLK6-siRNA-249 treatment, along with the length and number of synapses (Fig. 4D). These results suggested that interference of KLK6 expression protected against injury to the synapse structure.

\section{siRNA-KLK6 alters the expression profile of neurons}

Transcriptome sequencing was performed on the neurons after transfection with siRNA-KLK6 or siRNANC to further investigate the mechanism underlying the KLK6-mediated inhibition on neuron cells. The transcriptome sequencing quality control is shown in Table S6. As shown in Figure 5A, interference of KLK6 expression resulted in the abnormal expression of 5861 genes, among which, compared with the siRNA-NC group, there were 2,205 upregulated DEGs and 3,658 downregulated DEGs in the siRNA-KLK6 group. GO functional analysis showed that all these DEGs were mainly enriched in GO terms associated with immune and cellular junction, for instance, immune system process, innate immune response, and cell adhesion (Figure 5B). KEGG pathway analysis showed that the DEGs were also mainly involved in cellular junction-related pathways, such as cell adhesion molecules and the ECM-receptor interaction pathway (Figure 5C). These results indicate that interference of KLK6 expression contributes to protect against damage to the synapse structure by neuronal immune regulation or cellular junction.

\section{KLK6 regulates neuronal synapse-related Appl2, Nav2, and Nrn1}

Five DEGs related to immune regulation or cellular junction and positive response to siRNA-KLK6 were selected for qRT-PCR verification. The qRT-PCR results showed that adaptor protein, phosphotyrosine interaction, PH domain, leucine zipper containing 2 (Appl2), neuron navigator 2 (Nav2), and neuritin 1 
(Nrn1) expression levels were significantly upregulated compared with those in the siRNA-NC group. The differences in the expression levels of toll-like receptor 2 and synaptic vesicle glycoprotein $2 \mathrm{c}$ were not significant in the siRNA-KLK6 group (Figure 6). Therefore, interference of KLK6 expression may affect the expressions of Appl2, Nav2, and Nrn1 to protect against damage to the synapse structure.

\section{Discussion}

Hydrocephalus is a neurological disease in which CSF abnormally accumulates in the ventricles and causes abnormal expansion of the ventricles. CSF produced by the intraventricular choroid plexus flows through the aqueduct to the fourth ventricle. It then flows to the subarachnoid space, where the free communication between the ventricle and the subarachnoid space is expressed as $\mathrm{CH}$ (Shim et al. 2014). In the United States alone, untreated hydrocephalus has a mortality rate of $>50 \%$, with an estimated annual treatment cost in children of $\$ 2$ billion (Simon et al. 2008). However, some traditional therapies for $\mathrm{CH}$ have saved the lives of a limited number of patients, and the clinical treatment of $\mathrm{CH}$ slowly progresses due to the unclear molecular mechanism of $\mathrm{CH}$. Hereon, proteomics sequencing was performed to initially screen $\mathrm{KLK} 6$ related to $\mathrm{CH}$, and neuronal cell experiments further confirmed that regulation of Appl2, Nav2, and Nrn1 expression by KLK6 is the potential molecular mechanism of $\mathrm{CH}$.

In this study, significantly differentially expressed KLK6 was screened based on proteome sequencing, and KLK6 was found to co-localize with neurons in vivo, inhibiting neuronal cell activity, differentiation, and synaptic growth. KLK6 is a member of the KLK-related peptidase family, whose members are prominent in various neurological disorders. For example, KLK8 inhibition increases the number of neuronal progenitor cells and neuroplasticity-promoting interaction partners and promotes SH-SY5Y cell proliferation (Munster et al. 2020). KLK7 deficiency aggravates the pathological features of amyloid- $\beta$ deposited by astrocytes in AD (Kidana et al. 2018). Both KLK6 and KLK10 expression were elevated in CSF of patients with AD and associated with CSF-Tau, as shown by fluoro-D-glucose-positron emission tomography (Goldhardt et al. 2019). Shaw and Diamandis revealed that the distribution and expression of 15 human kallikrein members were significantly different in human tissue, among which KLK6 was dominant in both the brain and CNS (Shaw \& Diamandis 2007). Based on the research of KLK family members and our experimental results, that is, $\mathrm{KLK} 6$ expression is upregulated in the $\mathrm{CH}$ group, we believe that $\mathrm{KLK} 6$ participates in the progression of $\mathrm{CH}$. Moreover, the present results on $\mathrm{KLK} 6$ are consistent with those of previous studies. Scarisbrick et al. corroborated that KLK6 enzyme cascade mediates spinal cord injury, including inhibition of neurite extension and cell adhesion (Scarisbrick et al. 2006). Diamandis et al. found that the KLK6 level in CSF of patients with AD was approximately threefold higher than that in controls (Diamandis et al. 2000). The findings of these studies support our conclusions and confirm that KLK6 is involved in neurological disorders.

In the present study, we found that inhibiting the expression of KLK6 led to the upregulation of Appl2, Nav2, and Nrn1 expression in neurons, which may be the potential mechanism of KLK6 inhibition to protect neuronal synaptic structures from damage. Appls are multifunctional adaptor proteins; Appl2 is an isoform of Appl1 that mediates the PI3K/Akt cascade to promote cortical neuronal survival (Wu et al. 
2020) and also contributes to the modulation of synaptic plasticity via coupling neuronal activity with chromatin remodeling (Liu et al. 2017). Thus, it is reasonable that Appl2 is involved in siRNA-KLK6mediated synaptic structural recovery. Nav2 mRNA localizes to synaptic junctions and functions in neurite outgrowth, axonal elongation, and migration of the external granular layer neurons, and Nav2 deficiency can lead to abnormal cerebellar development (McNeill et al. 2011). Thus, Nav2 may be involved in siRNA-KLK6-mediated synaptic structural restoration. Moreover, a previous study reported that Nrn1 was involved in neurite outgrowth, which could reverse synaptic defects and cognitive function impairment in mice (Piras et al. 2019). Nrn1 overexpression attenuated apoptosis, promoted axonal regeneration of retinal ganglion cells, and improved optic nerve crush rats (Huang et al. 2021). Thus, upregulation of Nrn1 expression mediated by siRNA-KLK6 was conducive to synaptic structural remodeling. Consequently, interference of KLK6 expression improves the number of neurons and synapses in patients with $\mathrm{CH}$, and the mechanism may be achieved by regulating Appl2, Nav2, and Nrn1 expression.

\section{Conclusion}

Mass spectrometry was used to perform proteomic analysis on CSF and found that KLK6 expression was significantly upregulated in CSF of patients with $\mathrm{CH}$ compared with patients without $\mathrm{CH}$. Furthermore, KLK6 was confirmed to be highly expressed in the neuronal cells of $\mathrm{CH}$ rats, and KLK6 was shown to inhibit synaptic protein expression and synapse formation. Moreover, after interference of KLK6 expression, the transcriptome profile was obtained, which showed that KLK6 may affect the neuronal cell structure by regulating the expression of Appl2, Nav2, and Nrn1. Our data might provide a new target and theoretical basis for the treatment of $\mathrm{CH}$ after $\mathrm{SAH}$.

\section{Declarations}

\section{Declarations}

Not applicable.

\section{Funding}

This work was supported by General projects of national natural science foundation of China (81671207).

\section{Competing interests}

The authors declared that they have no conflict of interest.

\section{Availability of data and materials}

The datasets used and/or analyzed during the current study are available from the corresponding author on reasonable request. The RNA-seq data generated in this study is available in National Center for 
Biotechnology Information under accession number PRJNA719985.

\section{Code availability}

Not applicable.

\section{Authors' contributions}

Conceptualization and Funding acquisition: X.C.; Data curation: L.Y., D.Z., X.Y., X.C., Y.L., A.Z.; Formal analysis: L.Y., D.Z., X.Y.; Experimental studies: L.Y., D.Z., X.Y., X.C., Y.L., A.Z., P.Z., F.W.; Software: L.Y., D.Z., X.Y., P.Z., F.W.; Writing - original draft \& review \& editing: All authors. All authors read and approved the final manuscript.

\section{Ethics approval}

The study protocol was approved by the Institutional Ethics Committee of the Affiliated Changzheng Hospital, The Second Military Medical University.

\section{Consent to participate}

All participants were fully informed and signed written informed consent in this study.

\section{Patient consent for publication}

All the patients agree to publish the research.

\section{References}

Barkovits K, Linden A, Galozzi S, Schilde L, Pacharra S, Mollenhauer B, Stoepel N, Steinbach S, May C, Uszkoreit J, Eisenacher M, Marcus K (2018) Characterization of Cerebrospinal Fluid via Data-Independent Acquisition Mass Spectrometry. J Proteome Res 17: 3418-3430.

https://doi.org/10.1021/acs.jproteome.8b00308

Bayani J, Diamandis EP (2011) The physiology and pathobiology of human kallikrein-related peptidase 6 (KLK6). Clin Chem Lab Med 50: 211-233. https://doi.org/10.1515/CCLM.2011.750

Bernett MJ, Blaber SI, Scarisbrick IA, Dhanarajan P, Thompson SM, Blaber M (2002) Crystal structure and biochemical characterization of human kallikrein 6 reveals that a trypsin-like kallikrein is expressed in the central nervous system. J Biol Chem 277: 24562-24570. https://doi.org/10.1074/jbc.M202392200

Botfield H, Gonzalez AM, Abdullah O, Skjolding AD, Berry M, McAllister JP (2013) Decorin prevents the development of juvenile communicating hydrocephalus. Brain 136: 2842-2858. https://doi.org/10.1093/brain/awt203 
Chen X, Huang X, Li B, Zhao Z, Jiang L, Huang C, Lu Y (2010) Changes in neural dendrites and synapses in rat somatosensory cortex following neonatal post-hemorrhagic hydrocephalus. Brain Res Bull 83: 4448. https://doi.org/10.1016/j.brainresbull.2010.06.009

Cherian SS, Love S, Silver IA, Porter HJ, Whitelaw AG, Thoresen M (2003) Posthemorrhagic ventricular dilation in the neonate: development and characterization of a rat model. J Neuropathol Exp Neurol 62: 292-303. https://doi.org/10.1093/jnen/62.3.292

Diamandis EP, Yousef GM, Petraki C, Soosaipillai AR (2000) Human Kallikrein 6 as a Biomarker of Alzheimer's Disease. Clin Biochem 33: 663-667. https://doi.org/10.1016/s0009-9120(00)00185-5

Drewes LR, Jones HC, Keep RF (2014) News from the editors of Fluids and Barriers of the CNS. Fluids Barriers CNS 11:13. https://doi.org/10.1186/2045-8118-11-13

Garcia-Caceres C, Lagunas N, Calmarza-Font I, Azcoitia I, Diz-Chaves Y, Garcia-Segura LM, Baquedano E, Frago LM, Argente J, Chowen JA (2010) Gender differences in the long-term effects of chronic prenatal stress on the HPA axis and hypothalamic structure in rats. Psychoneuroendocrinology 35: 1525-1535. https://doi.org/10.1016/j.psyneuen.2010.05.006

Goldhardt O, Warnhoff I, Yakushev I, Begcevic I, Forstl H, Magdolen V, Soosaipillai A, Diamandis E, Alexopoulos P, Grimmer T (2019) Kallikrein-related peptidases 6 and 10 are elevated in cerebrospinal fluid of patients with Alzheimer's disease and associated with CSF-TAU and FDG-PET. Transl Neurodegener 8: 25. https://doi.org/10.1186/s40035-019-0168-6

Huang T, Li H, Zhang S, Liu F, Wang D, Xu J (2021) Nrn1 Overexpression Attenuates Retinal Ganglion Cell Apoptosis, Promotes Axonal Regeneration, and Improves Visual Function Following Optic Nerve Crush in Rats. J Mol Neurosci 71: 66-79. https://doi.org/10.1007/s12031-020-01627-3

Kawakita F, Kanamaru H, Asada R, Suzuki H (2019) Potential roles of matricellular proteins in stroke. Exp Neurol 322:113057. https://doi.org/10.1016/j.expneurol.2019.113057

Kidana K, Tatebe T, Ito K, Hara N, Kakita A, Saito T, Takatori S, Ouchi Y, Ikeuchi T, Makino M, Saido TC, Akishita M, Iwatsubo T, Hori Y, Tomita T (2018) Loss of kallikrein-related peptidase 7 exacerbates amyloid pathology in Alzheimer's disease model mice. EMBO Mol Med 10: e8184.

https://doi.org/10.15252/emmm.201708184

Kryza T, Bock N, Lovell S, Rockstroh A, Lehman ML, Lesner A, Panchadsaram J, Silva LM, Srinivasan S, Snell CE, Williams ED, Fazli L, Gleave M, Batra J, Nelson C, Tate EW, Harris J, Hooper JD, Clements JA (2020) The molecular function of kallikrein-related peptidase 14 demonstrates a key modulatory role in advanced prostate cancer. Mol Oncol 14:105-128. https://doi.org/10.1002/1878-0261.12587

Le Large TYS, El Hassouni B, Funel N, Kok B, Piersma SR, Pham TV, Olive KP, Kazemier G, van Laarhoven HWM, Jimenez CR, Bijlsma MF, Giovannetti E (2019) Proteomic analysis of gemcitabine-resistant 
pancreatic cancer cells reveals that microtubule-associated protein 2 upregulation associates with taxane treatment. Ther Adv Med Oncol 11:1758835919841233. https://doi.org/10.1177/1758835919841233

Liu Z, Xiao T, Peng X, Li G, Hu F (2017) APPLs: More than just adiponectin receptor binding proteins. Cell Signal 32: 76-84. https://doi.org/10.1016/j.cellsig.2017.01.018

Martinez-Morillo E, Diamandis A, Romaschin AD, Diamandis EP (2012) Kallikrein 6 as a serum prognostic marker in patients with aneurysmal subarachnoid hemorrhage. PLoS One 7:e45676. https://doi.org/10.1371/journal.pone.0045676

Mayford M, Siegelbaum SA, Kandel ER (2012) Synapses and memory storage. Cold Spring Harb Perspect Biol 4: a005751. https://doi.org/10.1101/cshperspect.a005751

McNeill EM, Klockner-Bormann M, Roesler EC, Talton LE, Moechars D, Clagett-Dame M (2011) Nav2 hypomorphic mutant mice are ataxic and exhibit abnormalities in cerebellar development. Dev Biol 353: 331-343. https://doi.org/10.1016/j.ydbio.2011.03.008

Minta K, Cullen NC, Nimer FA, Thelin EP, Piehl F, Clarin M, Tullberg M, Jeppsson A, Portelius E, Zetterberg $\mathrm{H}$, Blennow K, Andreasson U (2019) Dynamics of extracellular matrix proteins in cerebrospinal fluid and serum and their relation to clinical outcome in human traumatic brain injury. Clin Chem Lab Med 57: 1565-1573. https://doi.org/10.1515/cclm-2019-0034

Munster Y, Keyvani K, Herring A (2020) Inhibition of excessive kallikrein-8 improves neuroplasticity in Alzheimer's disease mouse model. Exp Neurol 324: 113-115.

https://doi.org/10.1016/j.expneurol.2019.113115

Muytjens CM, Vasiliou SK, Oikonomopoulou K, Prassas I, Diamandis EP (2016) Putative functions of tissue kallikrein-related peptidases in vaginal fluid. Nat Rev Urol 13: 596-607.

https://doi.org/10.1038/nrurol.2016.161

Ogawa K, Yamada T, Tsujioka Y, Taguchi J, Takahashi M, Tsuboi Y, Fujino Y, Nakajima M, Yamamoto T, Akatsu H, Mitsui S, Yamaguchi N (2000) Localization of a novel type trypsin-like serine protease, neurosin, in brain tissues of Alzheimer's disease and Parkinson's disease. Psychiatry Clin Neurosci 54: 419-426. https://doi.org/10.1046/j.1440-1819.2000.00731.x

Paliouras M, Borgono C, Diamandis EP (2007) Human tissue kallikreins: the cancer biomarker family. Cancer Lett 249: 61-79. https://doi.org/10.1016/j.canlet.2006.12.018

Piras IS, Krate J, Delvaux E, Nolz J, De Both MD, Mastroeni DF, Serrano GE, Sue LI, Beach TG, Coleman PD, Huentelman MJ (2019) Association of AEBP1 and NRN1 RNA expression with Alzheimer's disease and neurofibrillary tangle density in middle temporal gyrus. Brain Res 1719: 217-224.

https://doi.org/10.1016/j.brainres.2019.06.004

Page 13/21 
Scarisbrick IA, Sabharwal P, Cruz H, Larsen N, Vandell AG, Blaber SI, Ameenuddin S, Papke LM, Fehlings MG, Reeves RK, Blaber M, Windebank AJ, Rodriguez M (2006) Dynamic role of kallikrein 6 in traumatic spinal cord injury. Eur J Neurosci 24: 1457-1469. https://doi.org/10.1111/j.1460-9568.2006.05021.x

Shaw JL, Diamandis EP (2007) Distribution of 15 human kallikreins in tissues and biological fluids. Clin Chem 53: 1423-1432. https://doi.org/10.1373/clinchem.2007.088104

Shim JW, Sandlund J, Madsen JR (2014) VEGF: a potential target for hydrocephalus. Cell Tissue Res 358 : 667-683. https://doi.org/10.1007/s00441-014-1978-6

Simon TD, Riva-Cambrin J, Srivastava R, Bratton SL, Dean JM, Kestle JR (2008) Hospital care for children with hydrocephalus in the United States: utilization, charges, comorbidities, and deaths. J Neurosurg Pediatr 1: 131-137. https://doi.org/10.3171/PED/2008/1/2/131

Suzuki H, Fujimoto M, Kawakita F, Liu L, Nakano F, Nishikawa H, Okada T, Imanaka-Yoshida K, Yoshida T, Shiba M (2020) Toll-Like Receptor 4 and Tenascin-C Signaling in Cerebral Vasospasm and Brain Injuries After Subarachnoid Hemorrhage. Acta Neurochir Suppl 127:91-96. https://doi.org/10.1007/978-3-03004615-6_15

Wan W, Wang L, Chen X, Zhu S, Shang W, Xiao G, Zhang LK (2019) A Subcellular Quantitative Proteomic Analysis of Herpes Simplex Virus Type 1-Infected HEK 293T Cells. Molecules 24: 4215. https://doi.org/10.3390/molecules24234215

Wisniewski JR, Rakus D (2014) Multi-enzyme digestion FASP and the Total Protein Approach'-based absolute quantification of the Escherichia coli proteome. J Proteomics 109: 322-331. https://doi.org/10.1016/j.jprot.2014.07.012

Wu Y, Lv X, Wang H, Qian K, Ding J, Wang J, Hua S, Sun T, Zhou Y, Yu L, Qiu S (2020) Adaptor protein APPL1 links neuronal activity to chromatin remodeling in cultured hippocampal neurons. J Mol Cell Biol mjaa058. https://doi.org/10.1093/jmcb/mjaa058

$\mathrm{Xu} \mathrm{H}$ (2016) New concept of the pathogenesis and therapeutic orientation of acquired communicating hydrocephalus. Neurol Sci 37: 1387-1391. https://doi.org/10.1007/s10072-016-2589-7

Yang TC, Chang CH, Liu YT, Chen YL, Tu PH, Chen HC (2013) Predictors of shunt-dependent chronic hydrocephalus after aneurysmal subarachnoid haemorrhage. Eur Neurol 69: 296-303. https://doi.org/10.1159/000346119

\section{Figures}


A

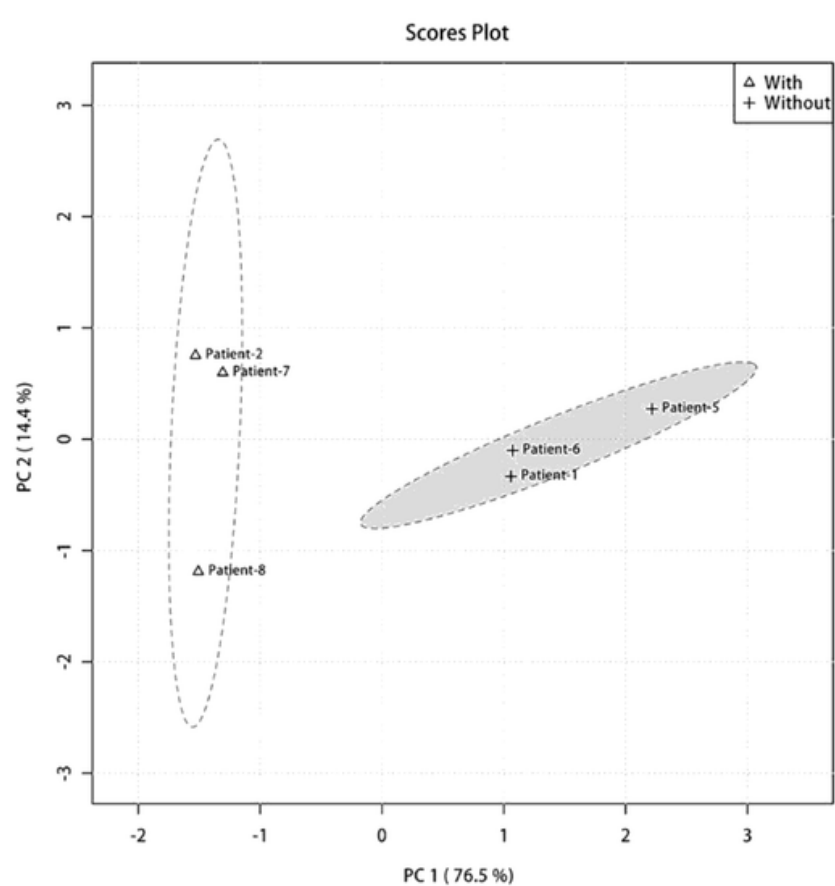

Volcano Plot

C

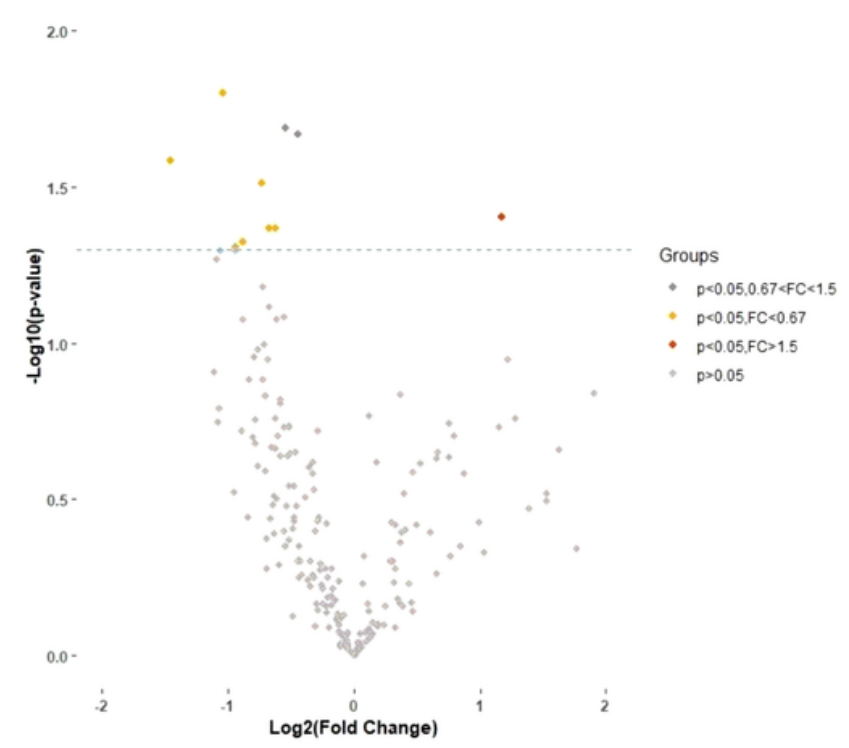

B

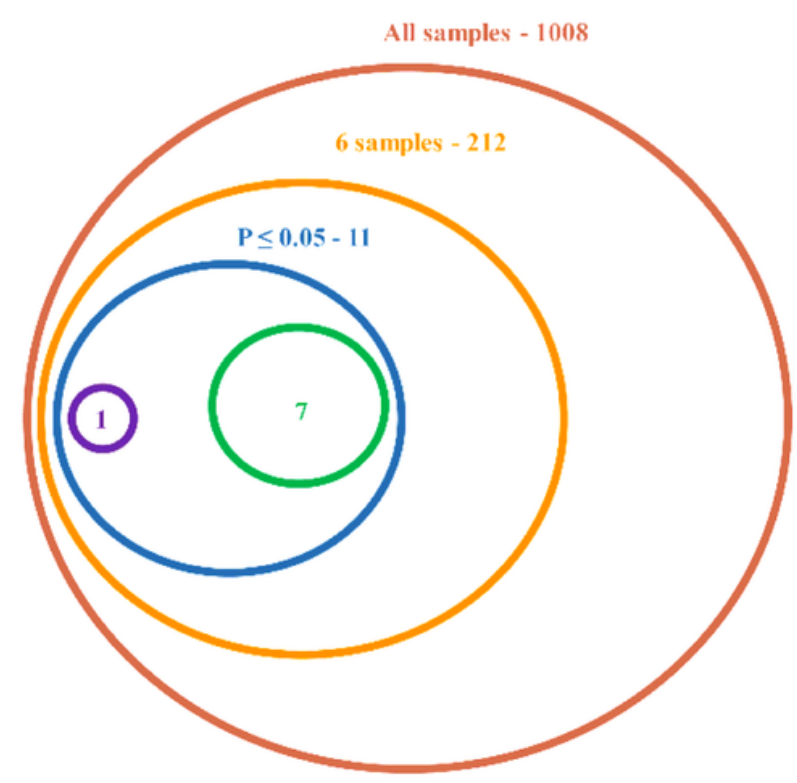

D

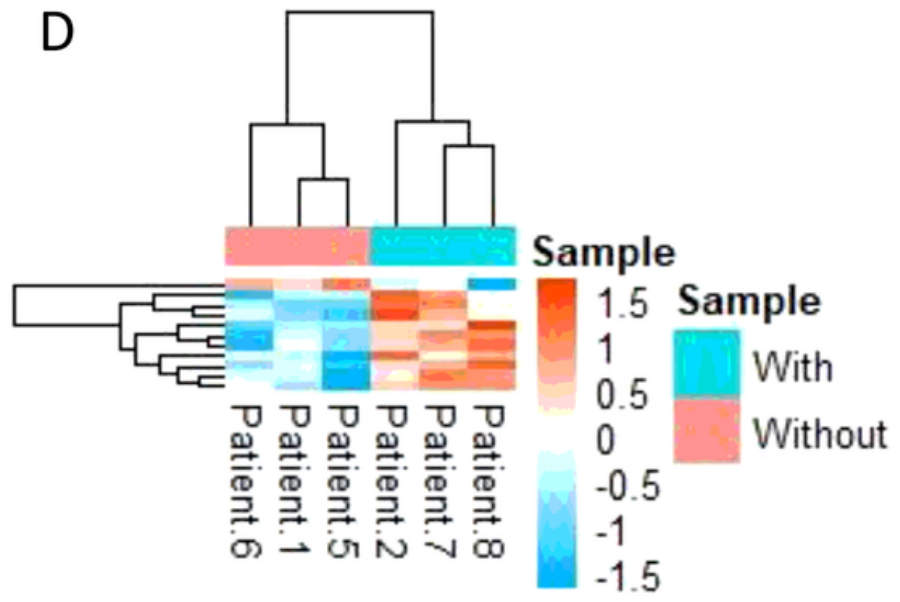

\section{Figure 1}

Identified DEPs between non-CH and CH A: PCA plots of 11 DEPs between non-CH and CH. "With" indicates patients with $\mathrm{CH}$ and "without" indicates patients without $\mathrm{CH}$. B: Number of proteins identified. A total of 1,008 proteins were identified from six samples; After decontamination, 212 proteins had quantitative information in six samples. Only 11 proteins were defined as DEPs, reaching $P<0.05$. Among them, 10 proteins were upregulated and one protein was downregulated in the $\mathrm{CH}$ group, compared with the non-CH group. C: Volcano plot of DEPs. D: Heatmap for significantly DEPs. "With" indicates patient samples and "without" indicates healthy control samples. 
A
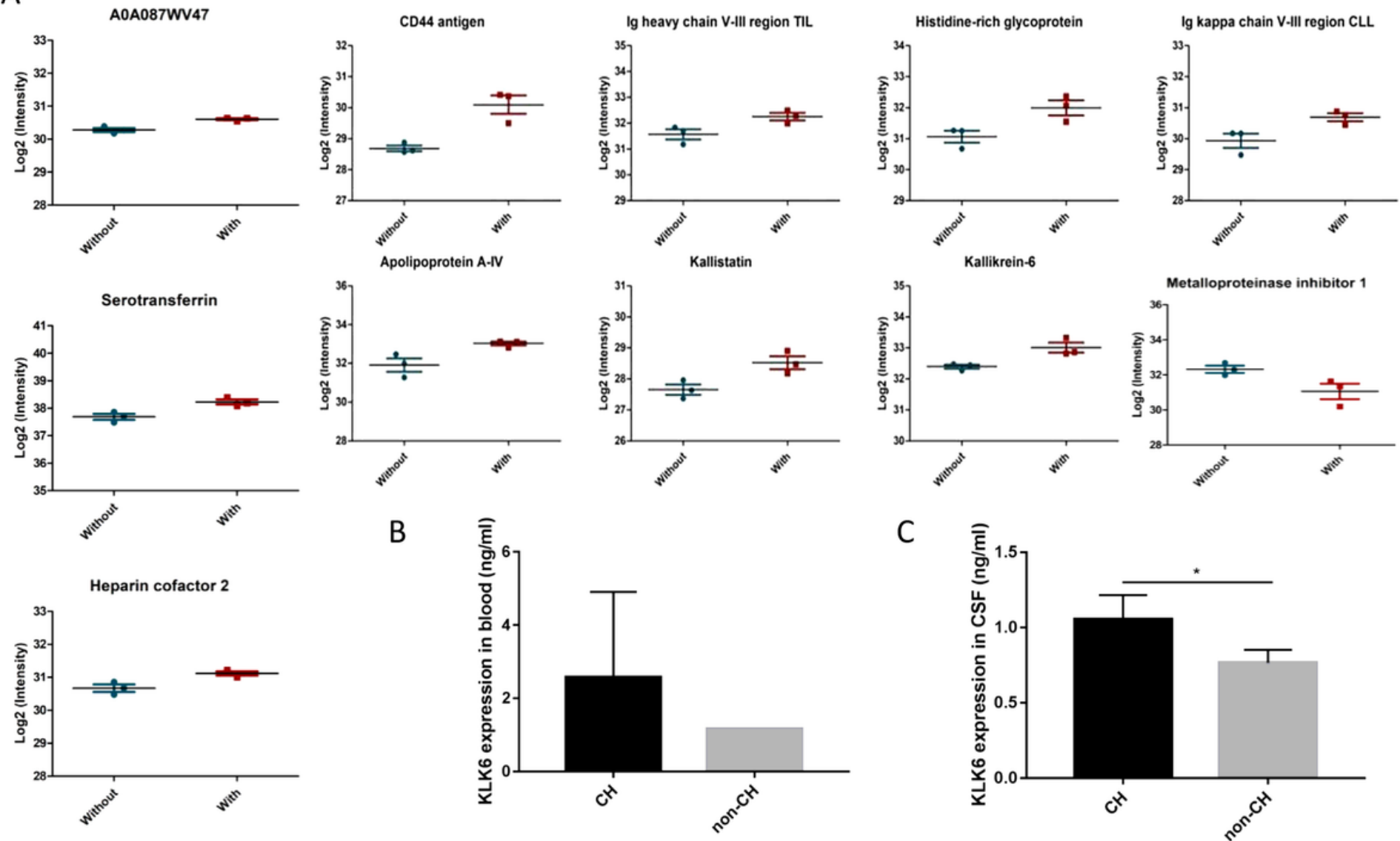

Figure 2

Intensity analysis of DEPs A: The intensity of DEPs was derived from the expression level of the non-CH group compared with the $\mathrm{CH}$ group. "With" represents the group of the $\mathrm{CH}$, and "without" represents patients without $\mathrm{CH}$. B: KLK6 protein levels in cerebrospinal fluid and blood were measured by ELISA. Assayed in duplicate and read in triplicate for total KLK6 protein concentrations SD with ELISA. 

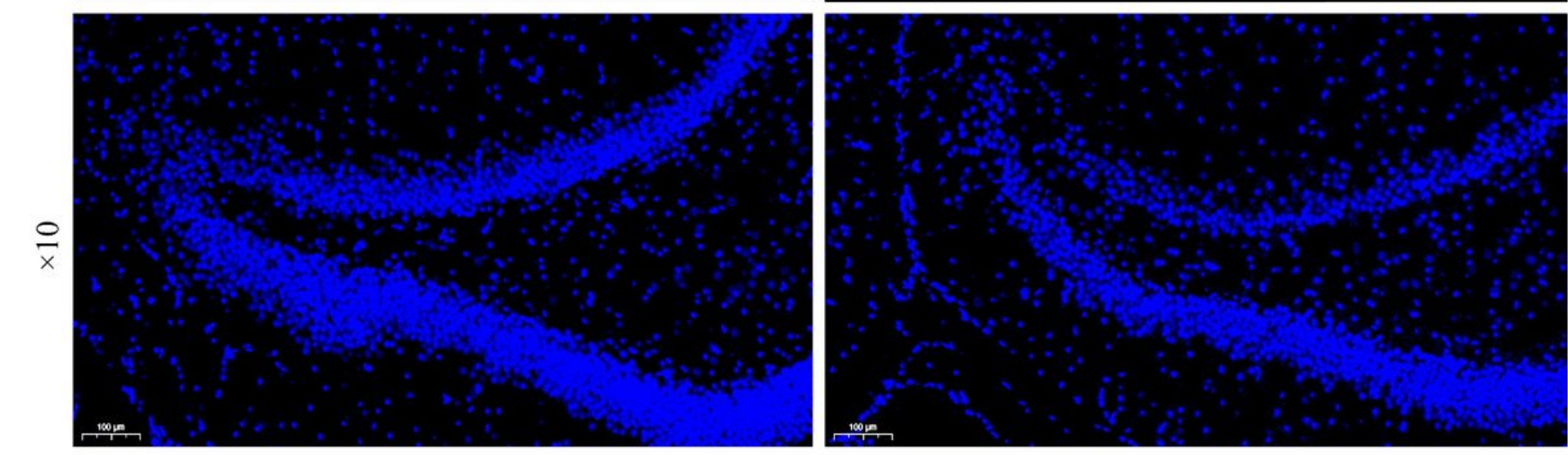

B

KLK6
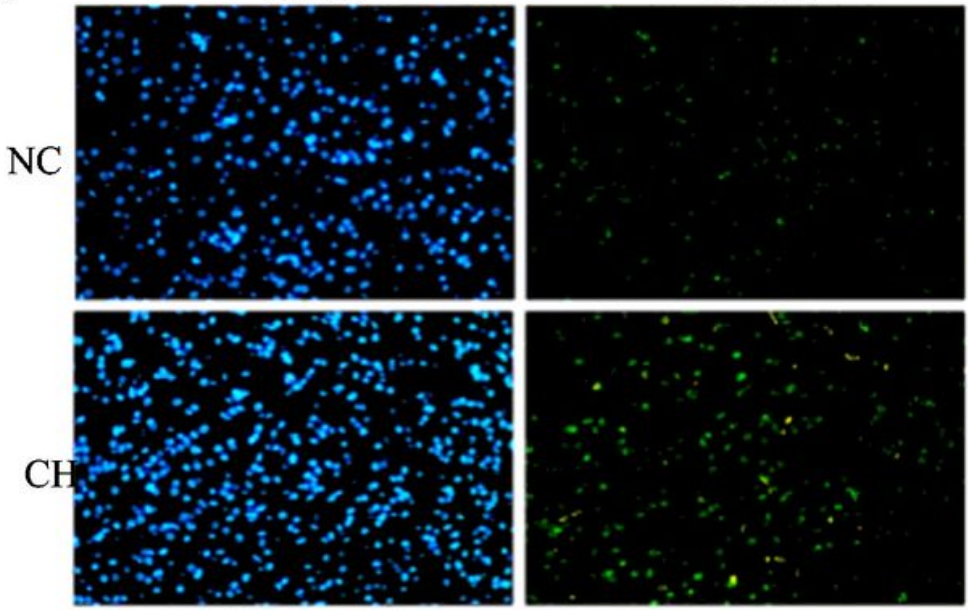

NeuN

Mege
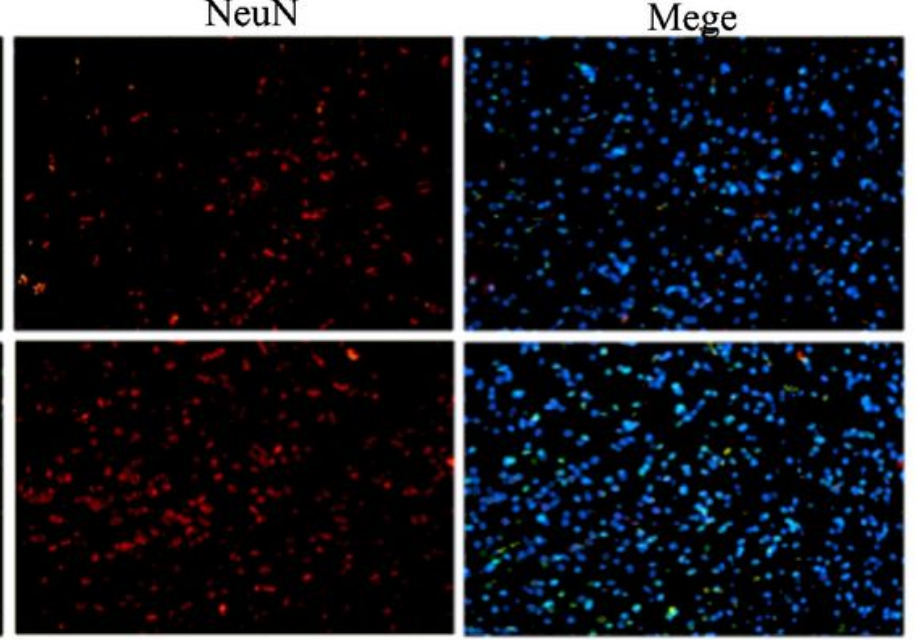

\section{Figure 3}

Expression of KLK6 and neurons in brain tissue A: Hoechst staining (scale bar, $100 \mu \mathrm{m})$. B: Double immunofluorescence staining of rat cortical neurons (100x). 


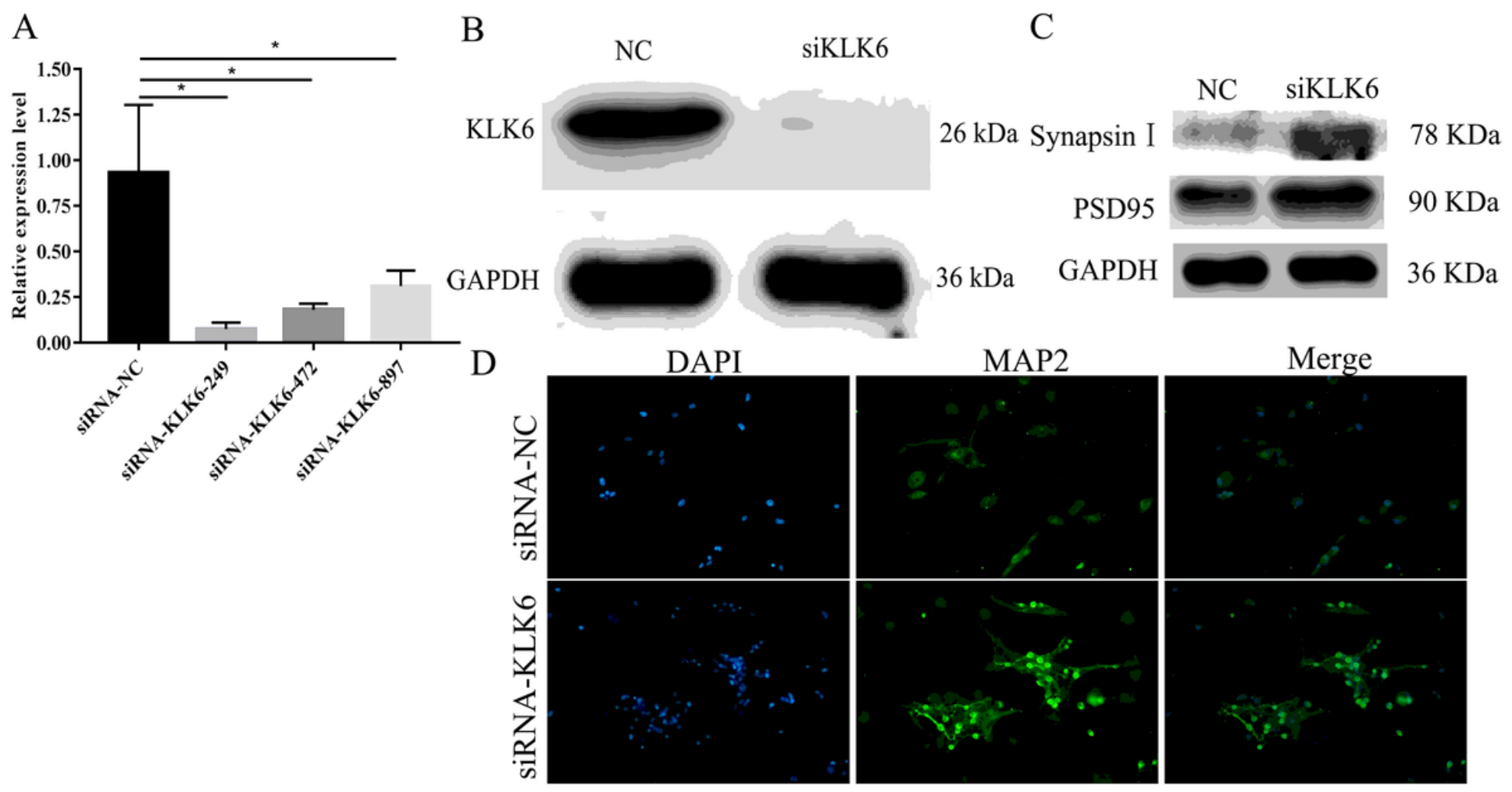

Figure 4

Effect of KLK6 on neuronal function Efficiency of siRNA interference of KLKL6 expression in neurons was detected using qRT-PCR (A) and western blotting (B). C: The expression levels of KLK6, synapsin-1, and PSD95 were determined using western blotting. D: Immunofluorescence staining of rat cortical neurons (400x). 
A

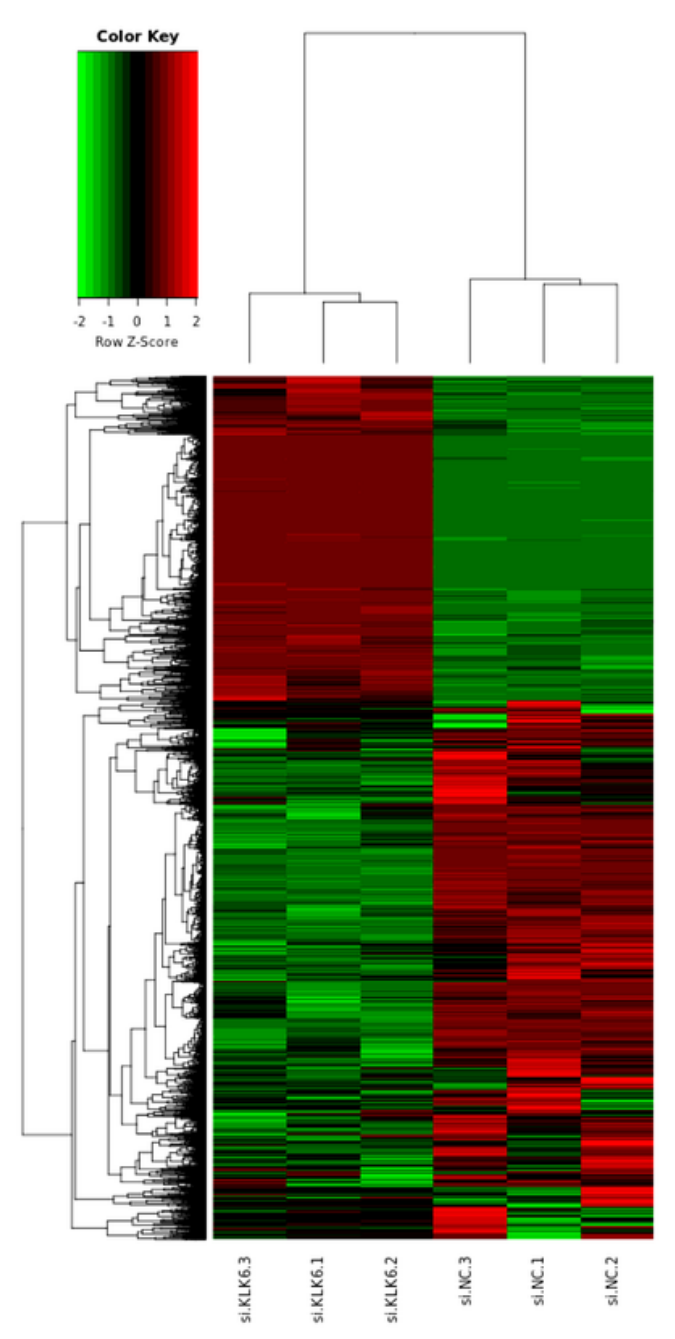

Top 20 of GO enrichment

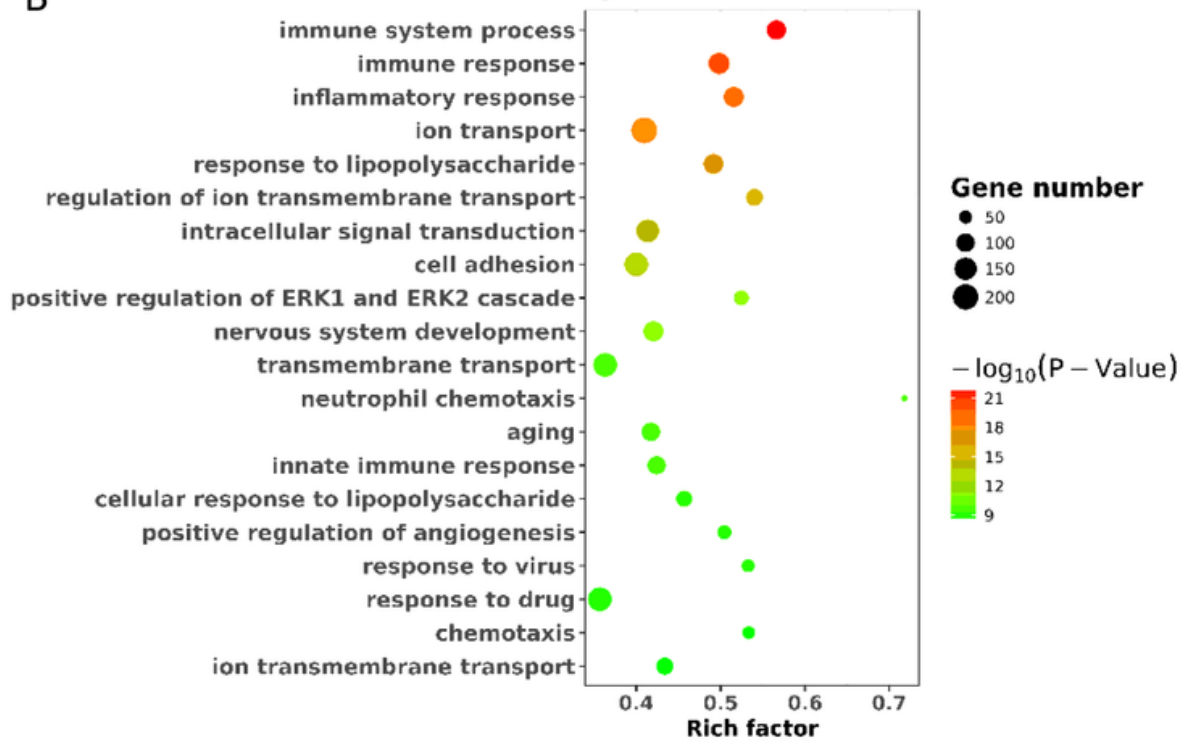

Top 20 of Pathway enrichment

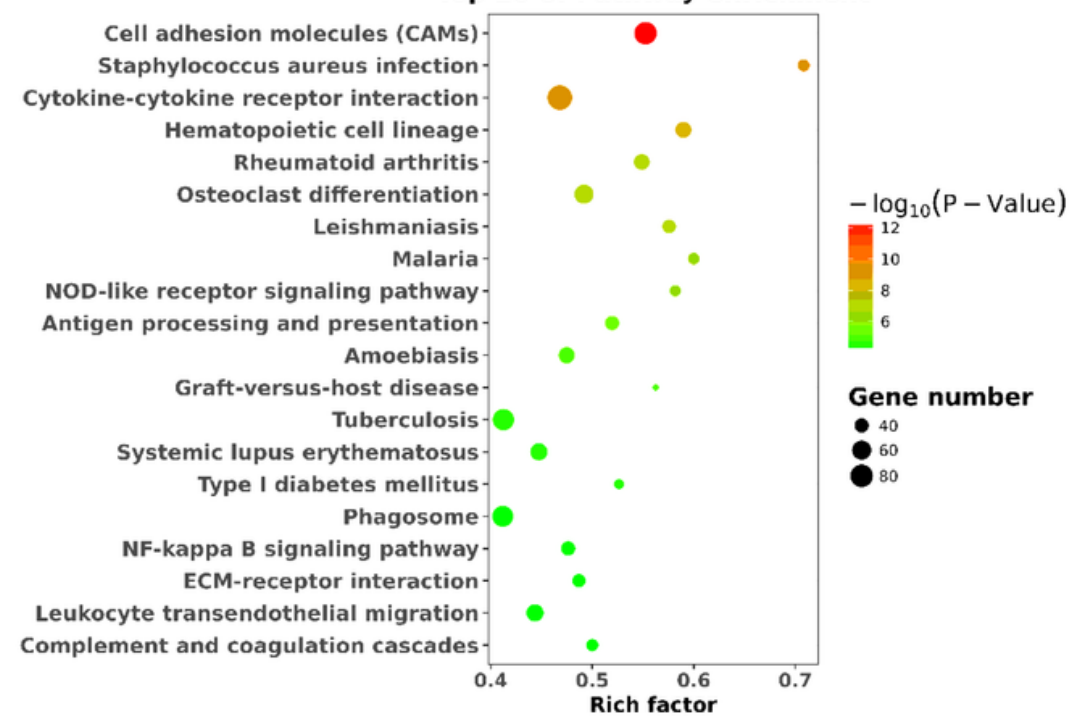

Figure 5

Transcriptome profile after interference of KLK6 expression A: Clustering heatmap for differentially expressed genes (DEGs) in neurons after transfection with siRNA-KLK6 or siRNA-NC. Red and green represent upregulated and downregulated DEGs expressed in the siRNA-KLK6 group compared with the siRNA-NC group. B: Top 20 GO enrichments for DEGs. C: Top 20 pathway enrichments for DEGs. 
Nav2

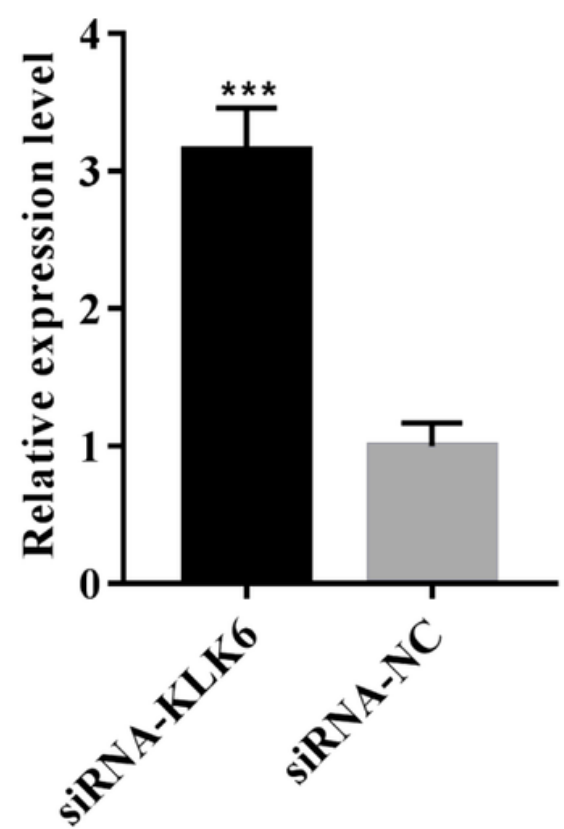

Sv2c

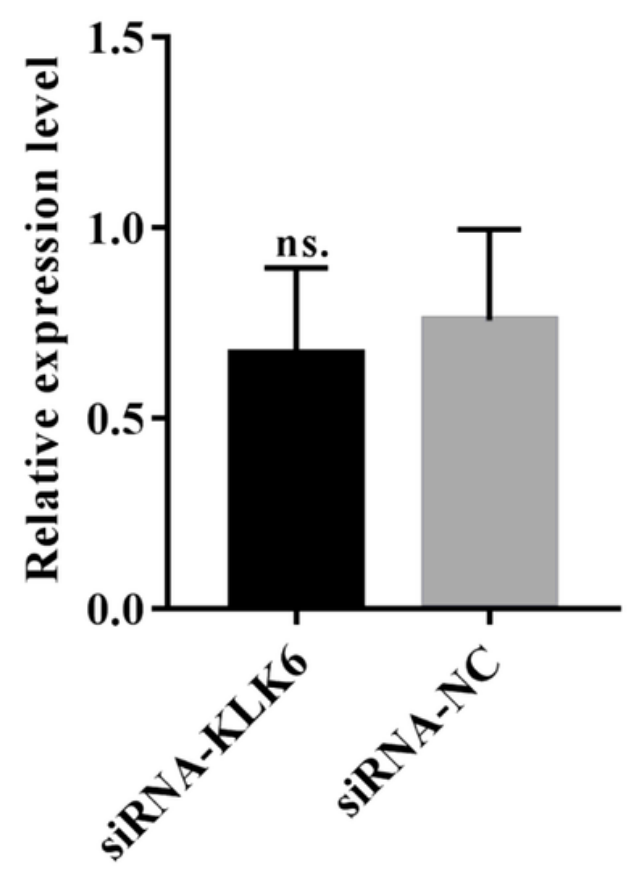

App12

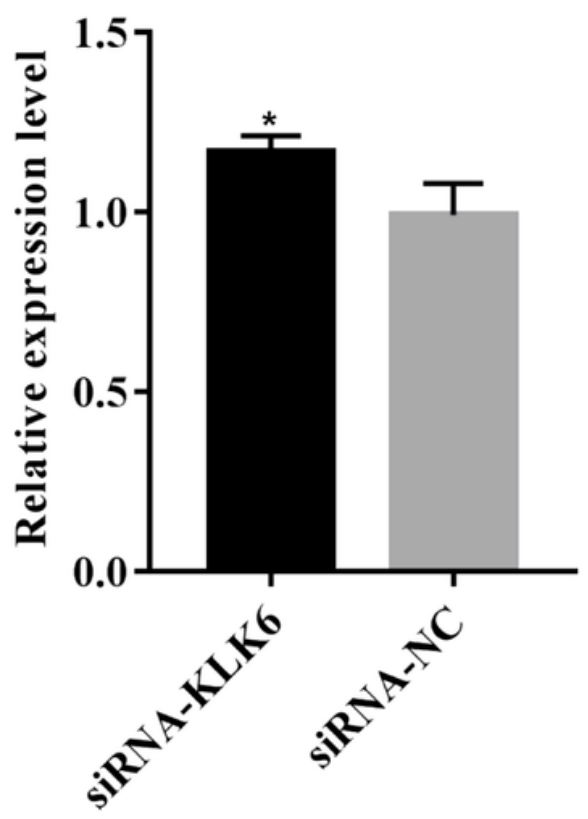

TLR2

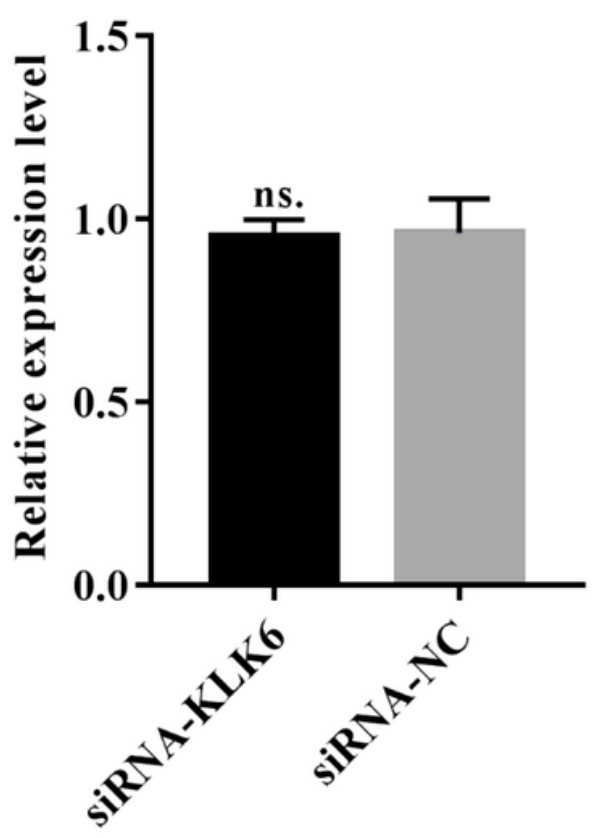

Nrn1

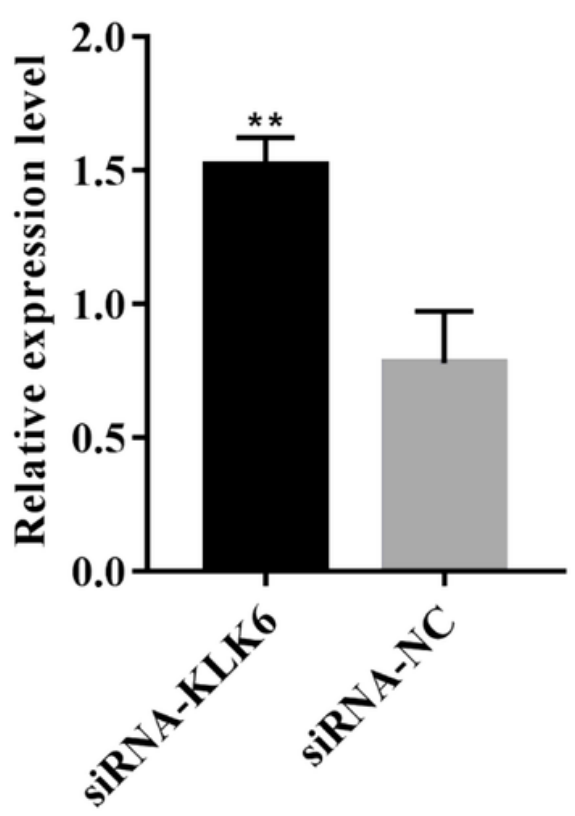

Figure 6

Verification of the expression of five DEGs using qRT-PCR Appl2: adaptor protein, phosphotyrosine interaction, $\mathrm{PH}$ domain and leucine zipper containing 2. Nav2: neuron navigator 2. Nrn1: neuritin 1. TLR2: toll-like receptor 2. Sv2c: synaptic vesicle glycoprotein 2 c. * indicates $P<0.05$, ** indicates $P<0.01$, *** indicates $\mathrm{P}<0.001$, ns. indicates $\mathrm{P}>0.05$.

\section{Supplementary Files}


This is a list of supplementary files associated with this preprint. Click to download.

- SupplementalFigure1.tif

- SupplementalFigure2.tif

- SupplementalTable1.docx

- SupplementalTable2.docx

- SupplementalTable3.docx

- SupplementalTable4.docx

- SupplementalTable5.docx

- SupplementalTable6.docx 